\title{
Adaptation Characteristics of Highly Qualified Boxers of Different Weight Categories to Non- Specific Load
}

\author{
Korzhenevskiy A.N. \\ Federal Scientific Center All-Russian Scientific-Research \\ Institute \\ korzhen-a@mail.ru
}

\author{
Klendar V.A. \\ Federal Scientific Center All-Russian Scientific-Research \\ Institute \\ bobz@rambler.ru
}

\author{
Kurguzov G.V. \\ Federal Scientific Center All-Russian Scientific-Research Institute \\ kurguzov-box@mail.ru
}

\begin{abstract}
Nowadays while training highly qualified boxers of different weight categories unified program of training is used. At the same time, the influence of the used physical loads on boxers' organism of different weight is not studied.

Testing on bicycle ergometer in a graduated load "to the limit" revealed considerable differences of adaptation among boxers of different weight categories.

The received results show the necessity to create individual programs for boxers with different body weight taking into account the characteristics of athletes' functional state.
\end{abstract}

Keywords-highly qualified boxers; aerobic and anaerobic functions; training; the power of the load; lactate concentration in blood.

\section{INTRODUCTION}

For an effective control over training process of boxers it is necessary to have objective information about the state of organism functional systems, which provide their working capacity. The absence of information doesn't give any chance to estimate the intensity of adaptation to the training and competitive loads, reserve capacities of an organism, "weak" points of training and doesn't provide correct training process planning.

During training process of boxers unified program of training is used, regardless of athletes weight categories. There were no research works connected with the characteristics of adaptation revelation among highly qualified boxers of different weight categories to bicycle ergometric load till "refusal" to work.

It is possible to get full information about athletes' functional readiness during the tests fulfillment "till the refusal" to work in terms of heart rate more than 180 beats/minute and maximum values of oxygen consumption (MOC) achievement $[2,3,6]$.

It is known that among highly qualified athletes the character of adaptation to non-specific load, fulfilled till the refusal to work, reflects the specificity of competitive activity [4].

During the competitive combat of highly qualified boxers maximum demands are placed on aerobic and anaerobic components of energy supply. Heart rate during the competitive combat increases more than the critical level, lactate concentration in blood after the combat is more than $11 \mathrm{mmol} / \mathrm{L}[5]$.

It is reasonable to use the indices of functional shifts in a competitive load as model characteristics for the training level estimation and boxers' training process correction.

The aim of the research - To define the characteristics of adaptation to bicycle ergometric load "till refusal" to work among highly qualified boxers of different weight categories.

\section{MATERIALS AND METHODS}

Among 19 highly qualified boxers (23-25 years-old), who had the categories of master of sports, World-class athlete, Merited Master of Sports, physical working capacity testing was held using stage increasing load "till refusal" to work at a bicycle ergometer. The initial stage of the load $675 \mathrm{kgm} / \mathrm{min}$, in terms of the following each stage of the load increase in 2 minutes for $225 \mathrm{kgm} / \mathrm{min}$ till "the limit". During the load fulfillment we registered heart rate every minute, during the second minute of each stage we made blood sampling for lactate concentration determination.

\section{RESULTS}

The boxers were examined during pre-competitive stage, at which specialized training prevailed (65\% SPT, 35\% GPT) with predominant use of intensive loads of aerobic-anaerobic, and sometimes glycolytic orientation. During functional readiness estimation we defined the groups of light weight categories $(52-60 \mathrm{~kg})$, average $(60-69 \mathrm{~kg})$ and heavy weight 
categories (more than $75 \mathrm{~kg}$ ) athletes.

During the data analysis we made a complex estimation using the following criteria:

a) ergometric indices of working capacity ( $\mathrm{W} \mathrm{kg}$, $\mathrm{t}$ of work).

b) the limit of transfer from one regimen of muscular work energy supply to another (aerobic, anaerobic, TANM (threshold of anaerobic metabolism)),

c) the factors, which limit working capacity (the reserve of cardiovascular system and inner environment of an organism).

Table 1 presents the results of testing physical working capacity of boxers during the load fulfillment at a bicycle ergometer.

TABLE 1. WORKING CAPACITY INDICES CHANGE AMONG BOXERS OF DIFFERENT WEIGHT CATEGORIES DURING ADAPTATION TO THE LOAD AT A BICYCLE ERGOMETER

\begin{tabular}{|l|c|c|c|c|c|}
\hline $\begin{array}{l}\text { Group/inde } \\
\mathrm{x}\end{array}$ & $\begin{array}{c}\mathrm{W} \text { of } \\
\text { work } \\
\mathrm{kgm} / \mathrm{kg}\end{array}$ & $\begin{array}{c}\mathrm{t} \text { of work, } \\
\mathrm{min}\end{array}$ & $\begin{array}{c}\mathrm{t} \text { TANM } \\
\mathrm{min}\end{array}$ & $\begin{array}{c}\text { HR max } \\
\text { beats/min }\end{array}$ & $\begin{array}{c}\mathrm{La} \\
\mathrm{mmol} / \mathrm{L}\end{array}$ \\
\hline $\begin{array}{l}\text { Boxers, } \\
\text { Light } \\
\text { weight } \\
\text { categories } \\
\text { (n=7) }\end{array}$ & $200 \pm 3,1$ & $\begin{array}{c}10,1 \pm 0,3 \\
2\end{array}$ & $6,1 \pm 0,31$ & $171,1 \pm 1,1$ & $\begin{array}{c}11,4 \pm 0,3 \\
7\end{array}$ \\
\hline $\begin{array}{l}\text { Boxers, } \\
\text { the average } \\
\text { weight } \\
\text { categories } \\
\mathrm{n}=6)\end{array}$ & $\begin{array}{c}246,6 \pm 4, \\
4\end{array}$ & $\begin{array}{c}13,4 \pm 0,3 \\
8\end{array}$ & $8,1 \pm 0,32$ & $\begin{array}{c}181,8 \pm 0,9 \\
4\end{array}$ & $\begin{array}{c}9,35 \pm 0,3 \\
5\end{array}$ \\
\hline $\begin{array}{l}\text { Boxers, } \\
\text { heavy } \\
\text { weight } \\
\text { categories } \\
\text { (n=6) }\end{array}$ & $197,0 \pm 3$, & $12,8 \pm 0,3$ & $10,1 \pm 0,4$ & $176,1 \pm 1,1$ & $8,0 \pm 0,31$ \\
\hline
\end{tabular}

The boxers of the average weight categories achieved the greatest power of work during the load fulfillment at a bicycle ergometer. At an ultimate work they have the activity of cardiovascular system increase (HR 181,8 $\pm 0,94$ beats/min), which proves maximum aerobic resources of energy mobilization and MOC achievement.

Glycolytic mechanism of energy supply in this load is not fully depleted. Lactate concentration in blood after the load shows the following value $-9,35 \pm 0,35 \mathrm{mmol} / \mathrm{L}$. (lower than the model level).

The boxers of heavy weight categories, in terms of lower level of working capacity in comparison with the athletes of the average weight, are characterized by greater steadiness of working capacity in the zone of aerobic energy supply. They are characterized by higher duration of work till TANM level $10,1 \pm 0,41$ minutes, among the average weight boxers: $8,1 \pm 0,32$ minutes. Great loads of aerobic orientation fulfillment (HR till 170 beats/min) provides aerobic potential and the power of aerobic mechanism of energy supply increase for intensive load fulfillment (it means threshold of anaerobic metabolism (TANM) increase) [1]. However, not high aerobic and anaerobic potential limits working capacity of heavy weight boxers (HR at the peak of the load among heavy weight boxers: $176,1 \pm 1,1$ beats/min doesn't achieve critical level, lactate concentration in blood is lower than $8,0 \pm 0,31 \mathrm{mmol} / \mathrm{L}$ in comparison with the average weight boxers: $9,35 \pm 0,35 \mathrm{mmol} / \mathrm{L})$.

Light weight boxers in case of almost the same power of the fulfilled load, as among heavy weight boxers are characterized by anaerobic orientation of energy supply predominance during adaptation to the load at a bicycle ergometer. Among them transfer to anaerobic type of energy supply happens quicker in comparison with the boxers of other weight categories: $6,1 \pm 0,31$ minutes. Speaking about heavy and average weight boxers, for working capacity preservation in terms of HR higher than TANM level (170 beats/min), they have maximum anaerobic glycolysis mobilization and lactate concentration in blood achieves high values (higher than a norm). Considerable anaerobic processes increase limits physical working capacity and maximum aerobic productivity of light weight boxers.

\section{CONCLUSION}

Thus, the used training loads among the average weight boxers provide physical working capacity increase and maximum aerobic productivity. Although the level of lactate concentration in blood doesn't achieve model values, for its increase it is necessary to use greater volume loads in the zone of submaximal intensity.

Among light weight boxers, general for all athletes volume of the training loads fulfillment, doesn't provide functional abilities increase. For working capacity increase among them it is necessary to use higher loads, which increase basic endurance (at TANM level) and work, connected with maximum aerobic abilities increase.

For heavy weight boxers it is reasonable to use great volume of aerobic-anaerobic orientation loads higher than TANM level (lactate concentration in blood from 4 till 7 $\mathrm{mmol} / \mathrm{L}$ ) and also the load, which increase maximum aerobic and anaerobic (glycolytic) abilities (HR higher than 180 beats/min, lactate concentration in blood in the zone of glycolytic energy supply, higher than $10 \mathrm{mmol} / \mathrm{L}$ ).

The received results prove that the use of unified program of training for highly qualified boxers with different weight is not effective enough. Individual programs of training creation for highly qualified boxers of different weight categories will provide high sports results achievement in the World arena.

\section{References}

[1] Avdeev Y. V., Tarakanov B.I., Vorobev V.Yu., Nerobeev N.Yu. Comparative analysis of competitive activity peculiarities among highly qualified free-style wrestlers of different gender. Scientific notes of P.F. Lesgaft University. 2009, vol. 6 (52), pp. 6-9.

[2] Belotserkovskiy Z.B. Ergometric and cardiac criteria of athletes' physical working capacity. Moscow: Soviet sport. 2005, 312 p.

[3] Graevskaya N.D, Goncharova G.A. Training level and sports fitness from the view of medicine. Modern technologies in sport medicine rehabilitation: materials of the Vth Russian scientific forum. Moscow. 2005, pp. 28-30.

[4] Korzhenevskiy A.N., Motylyanskaya R.E., Nevmyanov A.M. The results of non-specific samples and tests analysis among the representatives of different specializations. Theory and practice of physical culture. 1981, vol. 11 , pp. 21-24. 
[7] Faat A. Gatin. Methodology of technical readiness level increase among qualified boxers on the basis of an integrative approach. The Russian Journal of Physical Education and Sport. 2018, vol. 13(1), pp. 6-12. DOI: 10/14526/01_2018_278

[6] Souza Silveira R, Carlsohn A, Langen G, Mayer F, Scharhag-Rosenberger F. Reliability and day-to-day variability of peak fat oxidation during treadmill ergometry. J Int Soc Sports Nutr. 2016, Jan 25, vol. 13, pp. 4. 